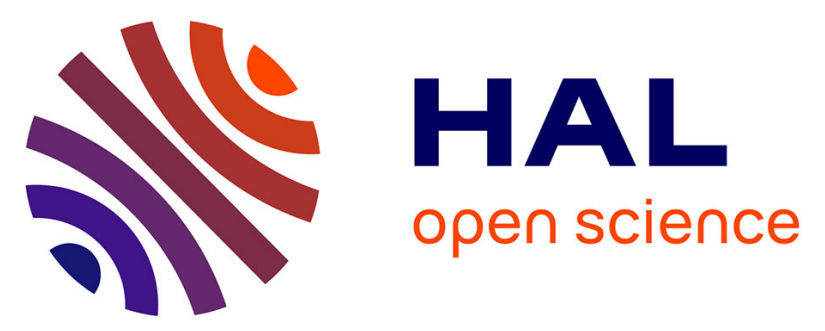

\title{
Optimization of aggregation-induced phosphorescence enhancement in mononuclear tricarbonyl rhenium(I) complexes: the influence of steric hindrance and isomerism
}

Jinhui Wang, Alexandre Poirot, Béatrice Delavaux-Nicot, Mariusz Wolff, Sonia Mallet-Ladeira, Jan Patrick Calupitan, Clémence Allain, Eric Benoist, Suzanne Fery-Forgues

\section{- To cite this version:}

Jinhui Wang, Alexandre Poirot, Béatrice Delavaux-Nicot, Mariusz Wolff, Sonia Mallet-Ladeira, et al.. Optimization of aggregation-induced phosphorescence enhancement in mononuclear tricarbonyl rhenium(I) complexes: the influence of steric hindrance and isomerism. Dalton Transactions, 2019, 48, pp.15906-15916. 10.1039/c9dt02786f . hal-02319009

\author{
HAL Id: hal-02319009 \\ https://hal.science/hal-02319009
}

Submitted on 17 Oct 2019

HAL is a multi-disciplinary open access archive for the deposit and dissemination of scientific research documents, whether they are published or not. The documents may come from teaching and research institutions in France or abroad, or from public or private research centers.
L'archive ouverte pluridisciplinaire HAL, est destinée au dépôt et à la diffusion de documents scientifiques de niveau recherche, publiés ou non, émanant des établissements d'enseignement et de recherche français ou étrangers, des laboratoires publics ou privés. 


\title{
Optimization of aggregation-induced phosphorescence enhancement in mononuclear tricarbonyl rhenium(I) complexes: the influence of steric hindrance and isomerism ${ }^{1}$
}

\author{
Jinhui Wang, ${ }^{\mathrm{a}, \mathrm{b}, \mathrm{c}}$ Alexandre Poirot, ${ }^{\mathrm{a}}$ Béatrice Delavaux-Nicot, ${ }^{\mathrm{d}, \mathrm{e}}$ Mariusz Wolff, ${ }^{\mathrm{f}}$ Sonia Mallet-Ladeira, ${ }^{\mathrm{g}}$ \\ Jan Patrick Calupitan, ${ }^{\mathrm{h}}$ Clémence Allain, ${ }^{\mathrm{h}}$ Eric Benoist ${ }^{\mathrm{a}}$ and Suzanne Fery-Forgues*a
}

\begin{abstract}
In order to improve the remarkable performance of a mononuclear tricarbonyl rhenium(I) complex (ReL1) that exhibits rare aggregation-induced phosphorescence enhancement (AIPE) behavior, two new complexes (ReL3 and ReL4) were prepared and investigated. They incorporate a 2-pyridyl-1,2,4-triazole (pyta) ligand connected to a 2-phenylbenzoxazole (PBO) moiety. Complex ReL3 differs from ReL1 by the presence of a bulky tert-butyl substituent, and ReL4 is an isomer where the PBO group is linked to the pyta ligand by its phenyl group. Theoretical calculations were in congruence with electrochemical and spectroscopic properties in solutions. Both new compounds exhibited strong AIPE and much better solid-state emission efficiency than ReL1, with photoluminescence quantum yields up to $55 \%$ for ReL4. Crystallographic data indicate that this increase in emission efficiency is due to optimum packing that prevents quenching. This work shows that minor structural changes may have major effects upon the solid-state spectroscopic properties and it provides a rational basis for accessing AIPE-active strongly emissive rhenium(I) complexes.
\end{abstract}

\section{Introduction}

Transition metal complexes that take advantage of aggregation to trigger light emission have been the subject of intense research in recent years for their potential applications as chemosensors, bioprobes, stimuli-responsive nanomaterials, and optoelectronic materials. ${ }^{1}$ Tricarbonyl rhenium(I) complexes have been known for a long time for their photoluminescence properties in solution, ${ }^{2}$ and their stability in air and water makes them appreciated cell imaging agents. ${ }^{3}$ In most cases, the predominant emission process is phosphorescence, whose long lifetime may bring benefits in terms of detection. The solid-state emission properties have also been studied, mainly in view of applications in the fields of optoelectronic and photonic devices. ${ }^{4}$ However, only rare examples of aggregation induced phosphorescence enhancement (AIPE) behavior have been reported, first concerning dinuclear ${ }^{5}$ and tetranuclear complexes, ${ }^{6}$ and more recently, mononuclear complexes. ${ }^{7}$ In a recent work, we showed that a mononuclear tricarbonyl rhenium(I) complex (ReL1, Fig. 1) exhibits clear AIPE behavior. In the solid state, this compound displays yellow to red emission, so it could be particularly valuable for preparing nanoparticles for bio-imaging, although the photoluminescence quantum yield is quite

\footnotetext{
${ }^{1}$ Electronic supplementary information (ESI) available: Experimental details, including proton numbering for NMR; crystal packing, molecular views, and CIF data; additional computational, electrochemical and spectroscopic data. CCDC 1922851 and 1922852. For ESI and crystallographic data in CIF or other electronic format see DOI: 10.1039/c9dt02786f

a SPCMIB, CNRS UMR5068, Université de Toulouse III Paul Sabatier, 118 route de Narbonne, 31062 Toulouse cedex 9 , France. E-mail: sff@chimie.ups-tlse.fr b Institute of Drug Discovery Technology, Ningbo University, Ningbo 315211, China

c State Key Laboratory of Chemical Oncogenomics, Key Laboratory of Chemical Biology, The Graduate School at Shenzhen, Tsinghua University, Shenzhen, Guangdong 518055, PR China d Laboratoire de Chimie de Coordination du CNRS, 205 route de Narbonne, BP 44099 F-31077 Toulouse Cedex 4, France e LCC-CNRS, Université de Toulouse, CNRS, Toulouse, France

f Institute of Chemistry, Department of Crystallography, University of Silesia, 9th Szkolna St., 40-006 Katowice, Poland g Service commun RX, Institut de Chimie de Toulouse, ICT- FR2599, Université de Toulouse III Paul Sabatier, 118 route de Narbonne, 31062 Toulouse cedex 9, France

h Laboratoire PPSM, CNRS UMR 8531, ENS Paris-Saclay, 61 avenue du Président Wilson, F-91230 Cachan, France
} 
modest $(0.065){ }^{8}$ The aim of the present work is now to improve the solid-state spectroscopic properties of these complexes through the rational design of the ligands.

To this end, two new compounds closely related to ReL1 were synthesized and studied. As a matter of fact, our previous study has revealed that ReL1, which incorporates the 3-(2-pyridyl )-1,2,4-triazole fragment, has superior emission properties compared to ReL2, built on the very popular 4-(2-pyridyl)1,2,3-triazole fragment. ${ }^{8}$ The appended 2-phenylbenzoxazole (PBO) moiety contributes to the conjugated electron system of these complexes, and restrictions on its molecular movements in the solid state are thought to be mainly responsible for the AIPE effect. Moreover, for the vast majority of PBO derivatives, there is little $\pi-\pi$ stacking interaction between aromatic groups, and hence an increased photoluminescence. ${ }^{9}$ In the first new complex (ReL3), the phenyl ring of the PBO moiety was substituted in position 4 with a tert-butyl group. The electronic structure is not expected to change with respect to ReL1, but the increased steric hindrance could influence the crystal packing mode, leading to differences in the solid-state emission properties. ${ }^{10}$ In the second complex (ReL4), the PBO moiety was connected to the pyta group by its phenyl ring. The substitution pattern of PBO is known to affect the emission properties in solution, ${ }^{11}$ so it is also expected to influence luminescence in the solid-state. The spectroscopic behavior of these two new compounds shows how simple structural modifications of the starting complex ReL1 may induce remarkable effects upon the solidstate emission properties. A thorough experimental and theoretical study supports these findings.

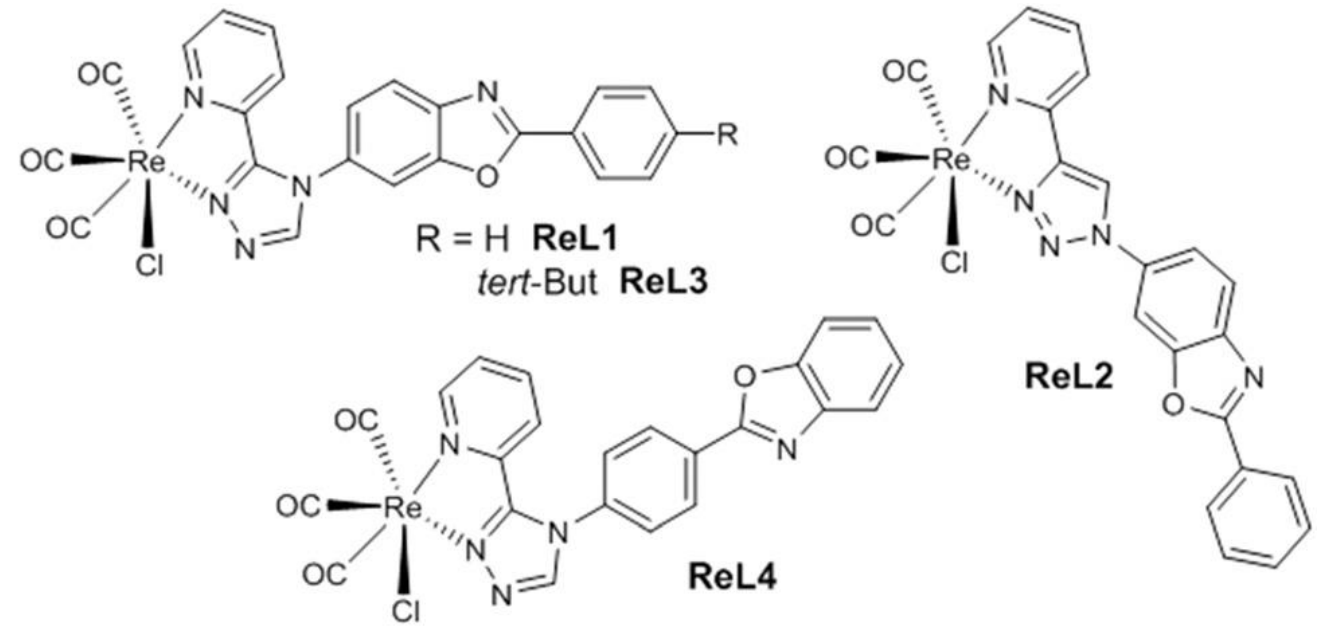

Figure 1. Chemical structures of the rhenium(I) complexes.

\section{Results and discussion}

\section{Synthesis}

Complexes ReL3 and ReL4 were obtained by following the synthesis pathways summarized in Fig. 2 and 3 , respectively. Detailed procedures and characterizations are given in the Experimental section. On the one hand, 2-amino-5-nitrophenol was reacted with 4-tert-butylbenzoic acid to give 6-nitro-4'tert-butyl-PBO (1), which then underwent a reduction process to afford the corresponding amine (2). On the other hand, 4'-amino-PBO (4) was directly obtained from the reaction of 2-aminophenol with 4 -aminobenzoic acid in the presence of polyphosphoric acid. These amino derivatives were condensed with a hydrazonamide derivative (3) to give ligands $\mathbf{L} 3$ and $\mathbf{L} 4$ with an overall yield of $64 \%$ and $56 \%$, respectively. These ligands were then reacted with $\left[\operatorname{Re}(\mathrm{CO})_{5} \mathrm{Cl}\right]$ in refluxing methanol to afford the corresponding tricarbonylrhenium(I) complexes ReL3 and ReL4 in good yields (71\% and 92\%, respectively). Ligands and complexes were unambiguously identified by ${ }^{1} \mathrm{H}$ and ${ }^{13} \mathrm{C} N M R$ spectroscopy, high resolution mass spectrometry and elemental microanalysis. The infrared spectra showed the characteristic $\mathrm{v}(\mathrm{CO})$ stretching bands of the fac- $\left[\operatorname{Re}(\mathrm{CO})_{3}\right]^{+}$unit at $2028,1920,1883 \mathrm{~cm}^{-1}$ 
for ReL3, and 2021, 1934, $1887 \mathrm{~cm}^{-1}$ for ReL4. The average values (1943 and $1947 \mathrm{~cm}^{-1}$, respectively) suggest that, in these complexes, ligand $\mathbf{L} \mathbf{3}$ is a slightly better electron donor than $\mathbf{L} \mathbf{4}$, according to Sarkar's theory. ${ }^{12}$<smiles>Nc1ccc([N+](=O)[O-])cc1O</smiles>

(a)<smiles>CC(C)c1ccc(-c2nc3ccc([N+](=O)[O-])cc3o2)cc1</smiles>

1 (b)

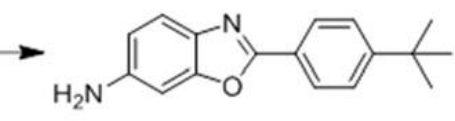

2

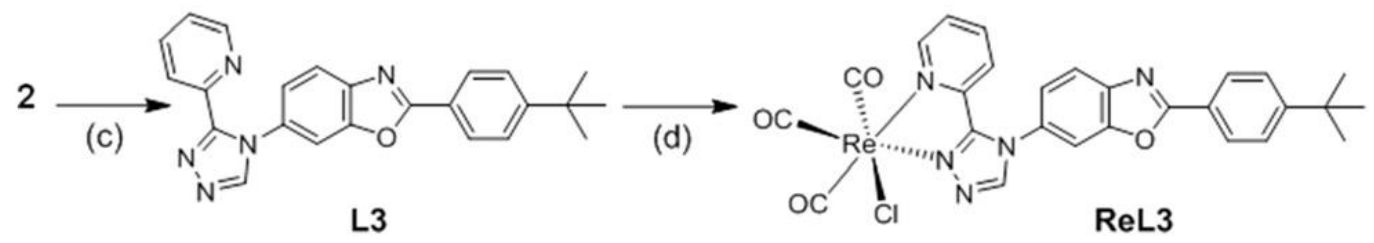

Figure 2. Synthesis of complex ReL3. Conditions and reagents: (a) 4-tertbutylbenzoic acid, polyphosphoric acid, $120^{\circ} \mathrm{C}, 16 \mathrm{~h}$ (75\%); (b) $10 \% \mathrm{Pd} / \mathrm{C}, \mathrm{H}_{2}, \mathrm{CH}_{3} \mathrm{OH} / \mathrm{CH}_{2} \mathrm{Cl}_{2}, 6$ bars, $24 \mathrm{~h}$ (82\%); (c) N,N-dimethyl-N'picolinoylformohydrazonamide (3), ${ }^{8}$ acetic acid, $\mathrm{CH}_{3} \mathrm{CN}, 90{ }^{\circ} \mathrm{C}, 24 \mathrm{~h}(64 \%) ;(\mathrm{d})\left[\operatorname{Re}(\mathrm{CO}){ }_{5} \mathrm{Cl}\right], \mathrm{MeOH}, 65{ }^{\circ} \mathrm{C}, 16 \mathrm{~h}$ (71\%).<smiles>[Z19]c1cc(-n2cnnc2-c2ccccn2)ccc1-c1nc2ccccc2o1</smiles>

Figure 3. Synthesis of complex ReL4. Conditions and reagents: (a) 4-Aminobenzoic acid, polyphosphoric acid, $220^{\circ} \mathrm{C}, 4 \mathrm{~h}(65 \%)$; (b) N,N-dimethyl- $\mathrm{N}^{\prime}$-picolinoylformohydrazonamide (3), ${ }^{8}$ acetic acid, $\mathrm{CH}_{3} \mathrm{CN}, 90{ }^{\circ} \mathrm{C}, 24 \mathrm{~h}$ (56\%); (c) $[\mathrm{Re}(\mathrm{CO}) 5 \mathrm{Cl}], \mathrm{MeOH}, 65^{\circ} \mathrm{C}, 16 \mathrm{~h}(92 \%)$.

\section{Crystal structures}

X-Ray quality crystals were obtained by diffusion of diethyl ether in DMF. Selected crystallographic data are given in the Experimental section, while bond lengths and angles are reported in Tables S1 and S2. + In both new complexes, the rhenium ion was coordinated to three carbonyl groups in a fac configuration, one chlorine atom, and two nitrogen atoms of the pyta ligand, with a moderate distortion of the octahedral geometry (Fig. 4). A comparison of the bond lengths and angles revealed that the structural modifications brought to ReL3 and ReL4 have little influence on the geometry of the coordination sphere with respect to ReL1. The benzoxazole and phenyl ring were almost aligned in the same plane. Complexes ReL3 and ReL4 retained the most characteristic feature of ReL1, i.e. the marked bending between the PBO moiety and the 1,2,4-triazole group. The angle value was $62.8(3)^{\circ} / 72.5(4)^{\circ}$ for molecules $A$ and $B$ in the asymmetric unit of ReL3, and even reached $83.3(8)^{\circ}$ for ReL4 (see Fig. 5). It is noteworthy that the PBO group only had one position with respect to pyta in ReL3 and ReL4, while two very distinct positions were detected in ReL1. The only disorder observed for ReL3 comes from the free rotation of the tert-butyl group, and from the permutation between the chlorine atom and one $\mathrm{CO}$ group, which generates two isomers in almost identical proportions. For ReL4, no ligand disorder was observed, except a N/O swap with a 75/25 ratio in the five-membered PBO ring. 


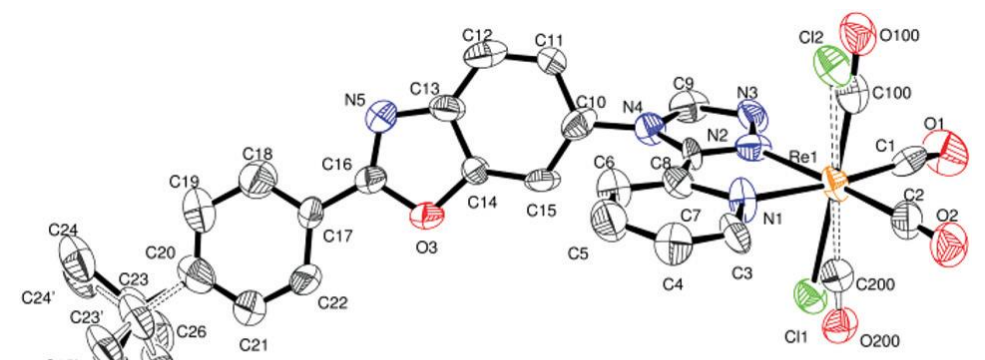

ReL3

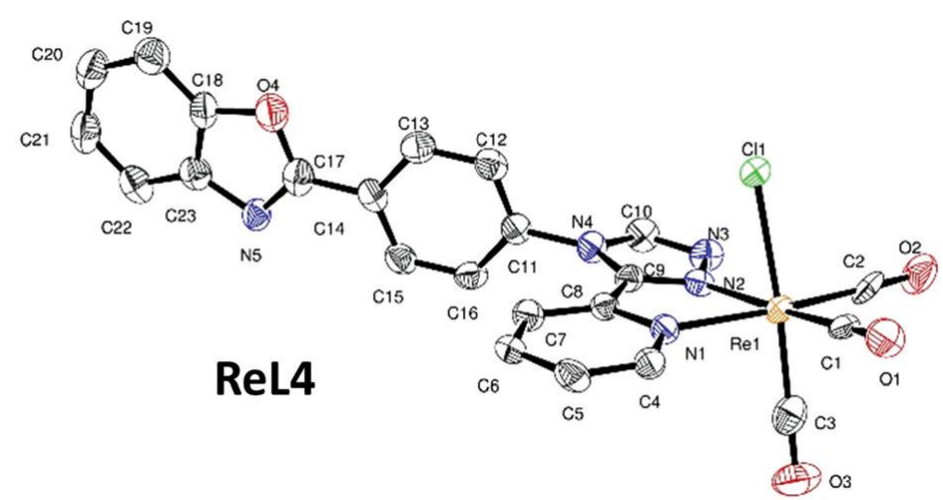

Figure 4. Molecular views of complexes ReL3 (one molecule of the asymmetric unit) and ReL4. Disorders are indicated by dashed lines and hydrogen atoms are not represented for the sake of clarity. Displacement ellipsoids are drawn at $50 \%$ probability

Regarding the molecular arrangement, complex ReL3 crystallized in the triclinic $\mathrm{P}^{-} 1$ space group with two molecules in the asymmetric unit. Both the inorganic moiety and the tert-butyl group strongly structured the network. In particular, the tert-butyl group was involved in several intermolecular short contacts with the oxygen atoms of the carbonyl groups, as well as with the carbon atoms of the pyridyl and phenyl groups of neighboring molecules. Other short contacts were found between the benzoxazole heteroatoms and the phenyl hydrogen atoms of neighboring molecules. To cope with the steric constraints due to the tert-butyl group and rhenium moiety, and minimize the neighboring interactions, the system adopts a head to head arrangement between two adjacent molecules, so that the rhenium centers and organic ligands constitute distinct layers (Fig. 5 and Fig. S1t). This arrangement is reminiscent of ReL1, with the major difference that in the latter complex the organic fragments are displayed in parallel planes with interactions occurring between triazole rings, while in ReL3 the organic moieties are arranged in different planes, so that no overlap of the aromatic systems was detected.

Complex ReL4 crystallized in the orthorhombic P212121 space group. The molecules formed antiparallel dimers (Fig. S1+). Certainly, switching the connection between the PBO moiety and the pyta group resulted in reduced steric hindrance with respect to ReL1, so that a head-to-tail arrangement is preferred. Dimers were themselves displayed in a herringbone manner. Only a tiny overlap was detected between the benzoxazole group of one molecule and the pyridyl group of the neighboring one (Fig. $\mathrm{S}^{+}+$). Consequently, $\pi-\pi$ stacking interactions are significantly minimized with respect to ReL1. 


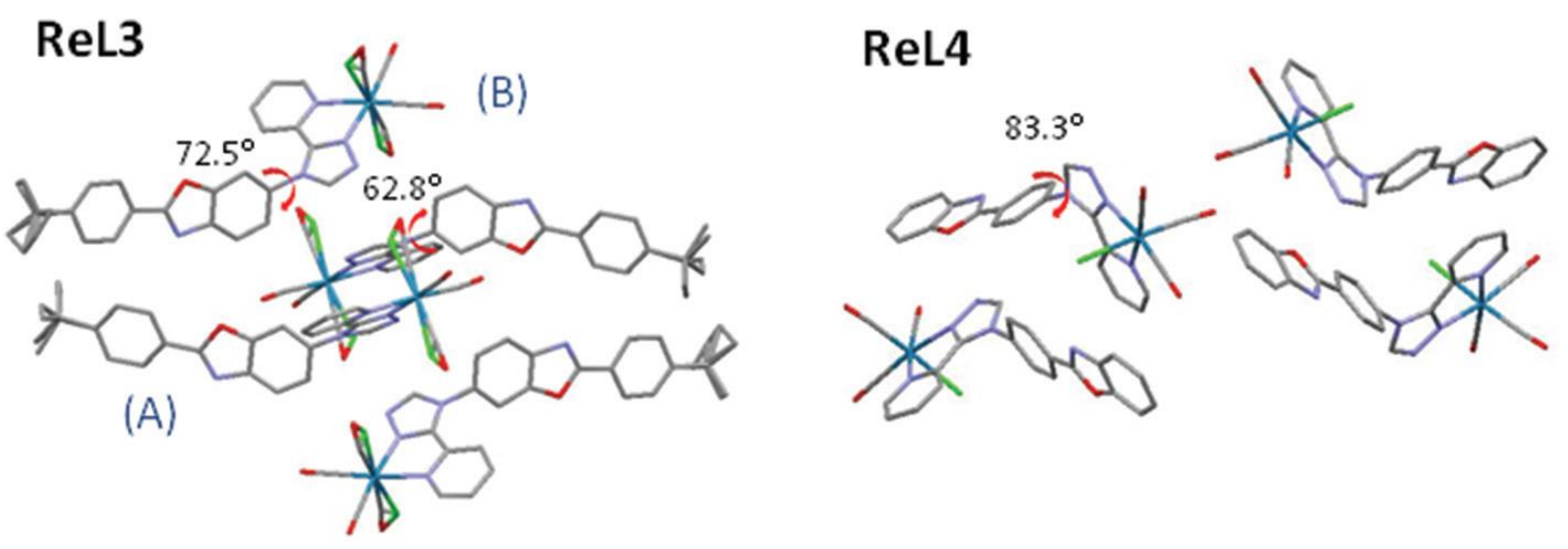

Figure 5. Crystal cells of complexes ReL3 and ReL4. Hydrogen atoms not represented for the sake of clarity.

\section{Electronic structure}

Computational studies based on the time dependent density functional theory (TD-DFT) method were performed considering the two complexes in dichloromethane (DCM). At the So ground state level, the energy-minimized structures were in good agreement with the data obtained by X-ray diffraction (Tables S3 and S4 ${ }^{\dagger}$ ). Differences can be related to packing effects, which are present in the X-ray determined structures and not taken into account by the calculation. The overall results show that both complexes are very similar from an electronic viewpoint (Tables S5 to S13+). The HOMO-2 and LUMO+1 are both centered on the PBO fragment, the HOMO-1 and HOMO are localized on the rhenium atom with contribution of the carbonyl and chlorine ligands, and the LUMO is localized on the pyta group (Table S5, Fig. 6, Fig. S3 and S4t). It is worth noting that the MOs of ReL3 and ReL1 are almost identical, indicating the very small contribution of the tert-butyl group. For ReL4, slight differences compared with ReL1 are found in the shape of PBO-centered orbitals, which change according to the connection to the triazole group. From an energetic viewpoint, both compounds have almost the same HOMO-LUMO gap. The first frontier orbitals have very similar energy levels, with the exception of the LUMO+1 that is slightly lower in ReL4 than in ReL3 (Fig. 6 and Fig. S5'). 
ReL3

LUMO+1
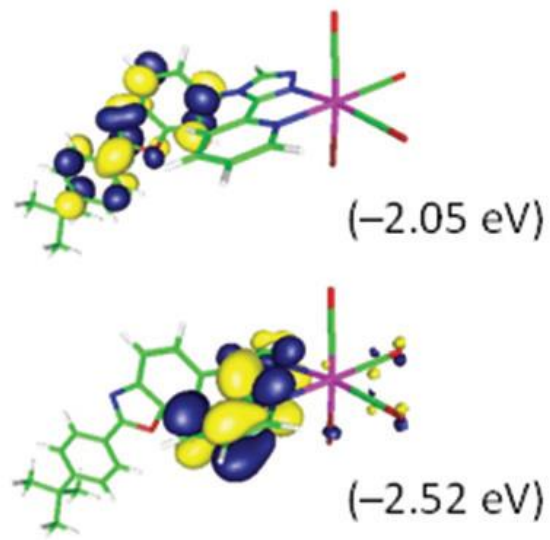

LUMO

HOMO

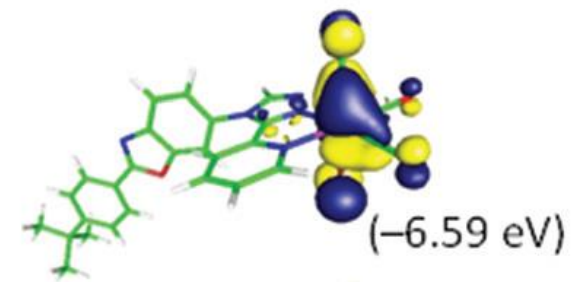

HOMO-1

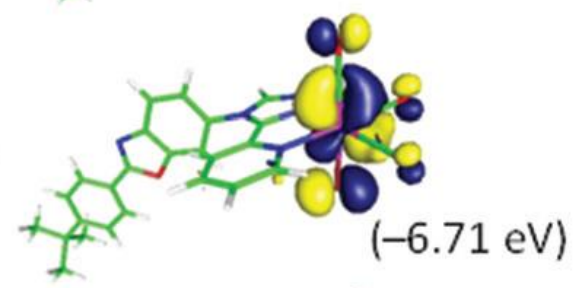

HOMO-2

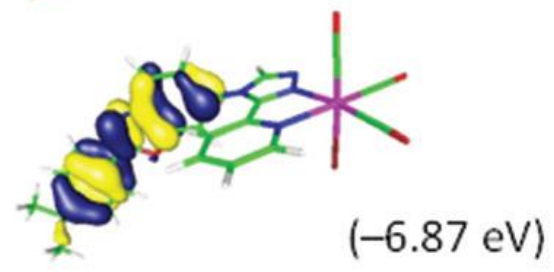

ReL4
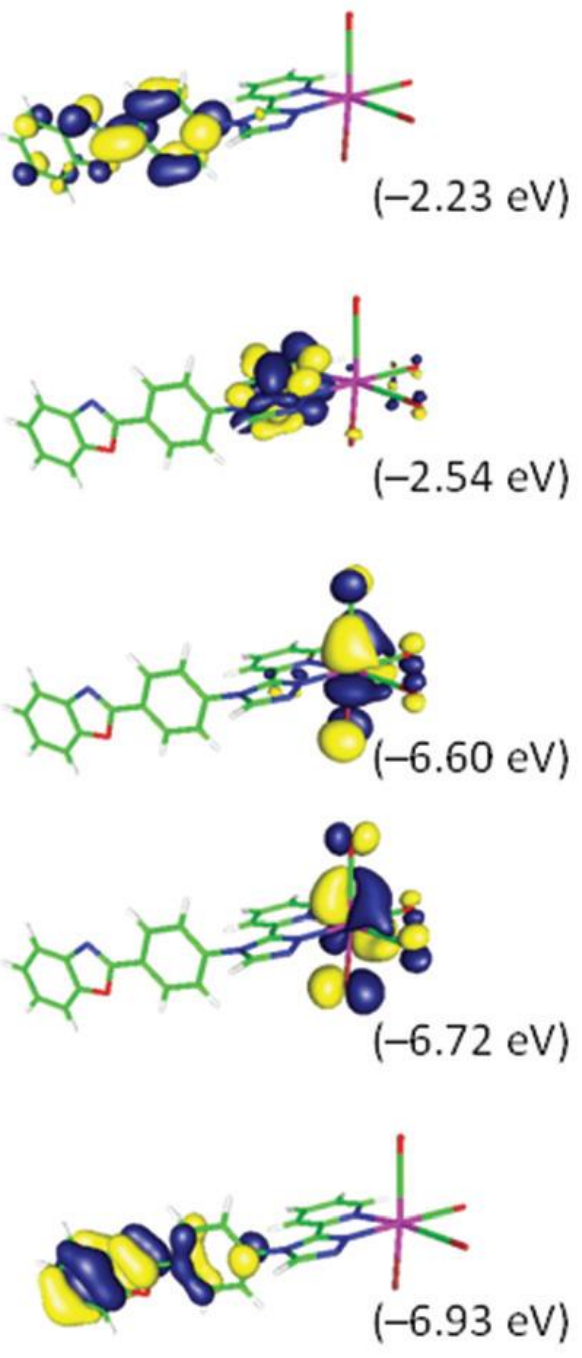

Figure 6. Isodensity plots of selected frontier molecular orbitals involved in the first electronic transitions of ReL3 and ReL4 in DCM, according to TD-DFT calculations at the PBE1PBE/LANL2DZ/6-31+G** level of theory.

\section{Electrochemical properties}

The electrochemical behavior of the new complexes was studied by cyclic voltammetry (CV) and Osteryoung square wave voltammetry (OSWV) measurements in DCM at room temperature. In the OSWV anodic part, the ReL3 and ReL4 complexes were characterized by two oxidation processes around 1.44 and $1.74 \mathrm{~V}$ (Table S14, Fig. S7 to S12†). The former process can be assigned to an irreversible Re(I) oxidation process. ${ }^{13}$ The reversibility of this process was not improved by a decrease or an increase in scan rate. Considering the OSWV cathodic part, both new complexes presented a reduction process beyond $-1.8 \mathrm{~V}$, as did ReL1. ${ }^{8}$ This process was most likely attributed to the reduction of the PBO fragment, confirming that the latter is not involved in the complexation process..$^{14}$ Indeed, a similar reduction process was detected for both ligands L3 and L4 (Table S14, Fig. S13 to S16+) and was also clearly visible by $\mathrm{CV}$. At more anodic potential around $-1.3 \mathrm{~V}$, another reduction process was observed for the complexes. It can be attributed to the reduction process of the substituted triazole ring whose potential value may substantially decrease by complexation as observed in related compounds. ${ }^{13,15}$ Remarkably, the value of this first reduction process seems to be characteristic of this family of complexes incorporating a 2-pyridyl-1,2,4-triazole ligand ${ }^{8}$ and could be 
related to the bent arrangement of the pyta and PBO moieties. In CV, the careful examination of the first reduction process at different scan rates showed that this process becomes quasireversible around $1 \mathrm{~V} \mathrm{~s}^{-1}$ for ReL3, as was the case for ReL1. For ReL4, the first reduction potential was 30 to 40 $\mathrm{mV}$ lower than for ReL3, and the rather uncommon quasi-reversibility of this process implying the pyta moiety was observed at a lower scan rate, i.e. $0.2 \mathrm{~V} \mathrm{~s}^{-1}$. Moreover, for both ReL3 and ReL4 complexes, a 1/1 intensity ratio was clearly evidenced between the first one-electron reduction process and the first one-electron oxidation process (Fig. 7).

All these trends are well supported by the TD-DFT calculations, which predict that the Re-centered HOMO on the one hand, and the pyta-centered LUMO on the other hand, are very close in energy for ReL1, ReL3 and ReL4. The experimental electrochemical HOMO-LUMO gap values $\left(E^{e l}\right)^{16}$ found for the ReL3 and ReL4 complexes ( 2.55 and $2.50 \mathrm{eV}$, respectively) also fit very well with the calculated ones ( 2.70 and $2.65 \mathrm{eV}$ ) (Table S15 ${ }^{\dagger}$ ). Finally, compared to ReL1, the inversion of the PBO connection (ReL4) perturbed slightly more the electronic properties in solution than the addition of a tert-Bu group on the phenyl moiety (ReL3).

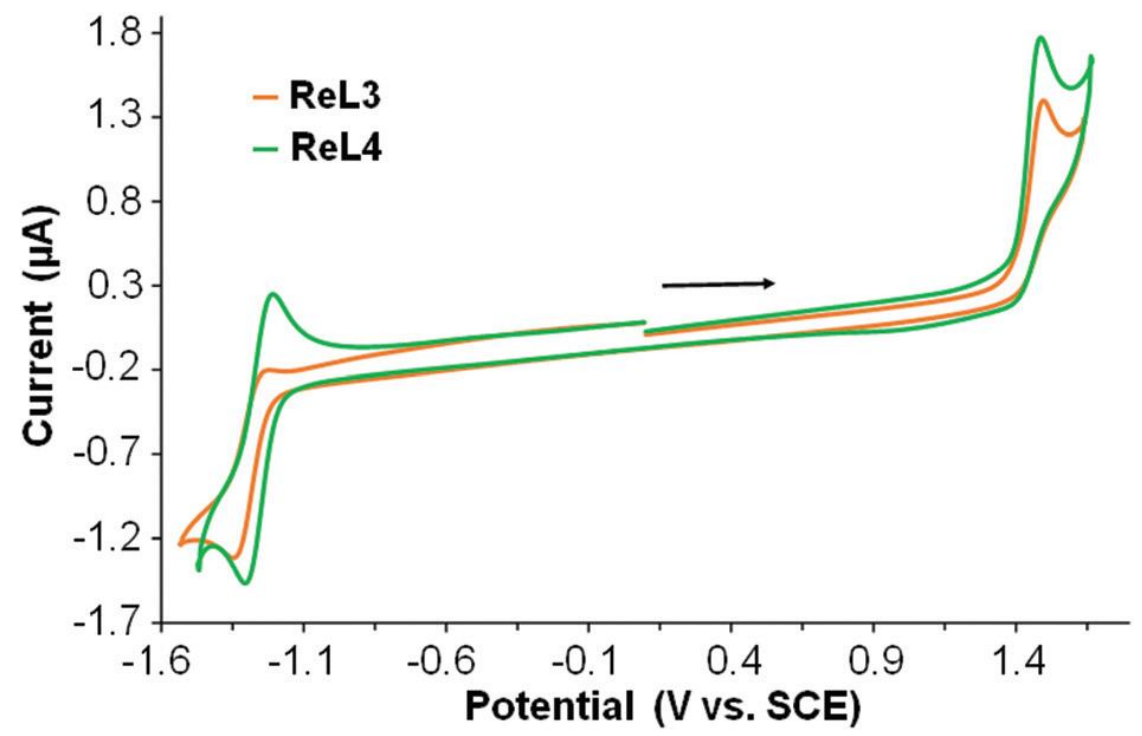

Figure 7. Segmented cyclic voltamograms of ReL3 (orange line) and ReL4 (green line) on a Pt working electrode in $\mathrm{CH}_{2} \mathrm{Cl}_{2}+0.1 \mathrm{M} \mathrm{n}\left[\mathrm{Bu}_{4} \mathrm{~N}\right]\left[\mathrm{BF}_{4}\right]$ at room temperature and at a scan rate of $0.2 \mathrm{~V} \mathrm{~s}^{-1}$ toward anodic potentials.

\section{UV-vis absorption spectra}

Experimentally, both complexes have very similar molar absorption coefficients and maximum absorption in various organic solvents (Table 1 and Table S17+). For instance, in DCM solutions, the absorption spectra showed an intense band around $305 \mathrm{~nm}$ and a distinct band of weak intensity above $380 \mathrm{~nm}$, in good agreement with calculations (Fig. 8, Tables S6 and S7 ${ }^{\dagger}$ ). The main contributor of the highest energy band was identified as a transition between HOMO-2 and LUMO+1 (Table S5+) with strong intraligand charge transfer (ILCT) character. The lowest energy band results from an HOMO-1 $\rightarrow$ LUMO transition, and can thus be assigned to metal to ligand charge transfer (MLCT). 
(a)

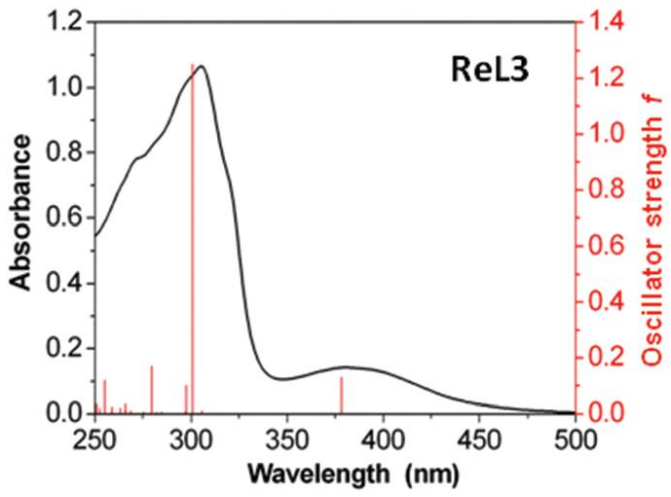

(b)

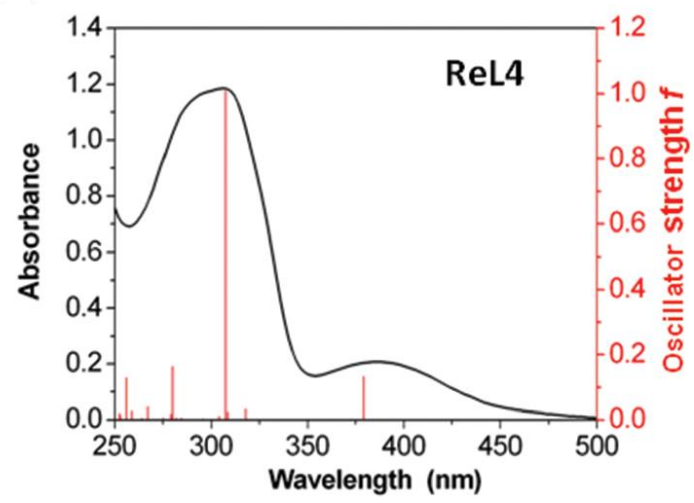

Figure 8. Experimental (black line) and simulated (red line) UV-vis absorption spectra of ReL3 (a) and ReL4 (b) in dichloromethane

\section{Emission properties}

The photoluminescence spectra in organic solvents were recorded upon excitation in the MLCT band $(380 \mathrm{~nm})$. Bubbling with argon only led to a small increase of intensity. The excitation spectra resembled the absorption spectra (Fig. $\mathrm{S17}^{\dagger}$ ). The emission spectra in DCM displayed an intense band centered on $627 \mathrm{~nm}$ for ReL3 and $632 \mathrm{~nm}$ for ReL4 (Table 1), with moderate quantum yields (0.017 and 0.012) and lifetimes of 80 and $100 \mathrm{~ns}$ (Fig. S18 and Table S16 ${ }^{\dagger}$ ), respectively. In acetonitrile and methanol, the emission spectra were shifted to short wavelengths and their intensity was slightly decreased (Table $\mathrm{S} 17+$ ). These spectroscopic properties are very close to those of ReL1. TD-DFT calculations predict that emission arising from the first triplet state should give bands peaking at $642.8 \mathrm{~nm}$ and $658.6 \mathrm{~nm}$ for ReL3 and ReL4 in DCM, respectively (Table S9†). The experimental data agree quite well with these values, and this red emission is therefore attributed to phosphorescence. It is noteworthy that the triplet states responsible for this emission have very similar electron distribution in both ReL3 and ReL4, with orbitals located on the rhenium center and its coordination sphere, including the pyta ligand (Fig. $\mathrm{S}^{+}{ }^{+}$). To highlight the AIPE effect, the complexes were dissolved in acetonitrile, and then the proportion of water was increased from 0 to $95 \%$, while keeping the complexes at constant concentration. Under these conditions, the phosphorescence quantum yield was markedly increased about 9 times for both complexes (Fig. 9). This effect was accompanied by the formation of aggregates, which were detected by UV-vis absorption spectroscopy in media containing $60 \%$ water or more (Fig. S20+). The largest aggregates were also observed by fluorescence microscopy, which confirms their luminescence properties. We further noted that the AIPE effect appeared at lower complex concentration and lower proportion of water for ReL4 than for ReL3, probably due to solubility differences between the two compounds.

Regarding the position of the emission spectra, a two-step behavior was noticed, more pronounced for ReL4 than for ReL3. Indeed, the emission spectra first went from red to yellow-green with the water proportion passing from 0 to $80 \%$, and then went back to orange-yellow for a higher proportion of water. The initial shift to short wavelengths may be attributed to a negative solvatochromic effect, similar to that observed for dissolved molecules with increasing the solvent polarity (Table S17 + ). This effect could arise from the large proportion of molecules situated at the surface of small aggregates, in contact with the medium. In contrast, the subsequent shift to long wavelengths could be assigned to a packing effect of bulk molecules, which become preponderant in large aggregates and are insensitive to solvent polarity.

The AIPE effect can be explained as follows. In solution, although limited by steric hindrance, movements of the PBO fragment with respect to the pyta group are possible, as well as the free rotation between the phenyl and benzoxazole rings of PBO. These movements may lead to a waste of excitation energy, hence to weak phosphorescence efficiency. The bimolecular quenching of phosphorescence by oxygen, although moderate in our case, acts in the same direction. In aggregates, 
molecular movements are restricted and the access of oxygen is limited, resulting in the observed phosphorescence enhancement, provided that the molecular arrangement is compatible with the emission of light. It must be emphasized that the aggregates formed in the water/ acetonitrile mixtures are in contact with water molecules, and their crystallinity is unknown.

Table 1. Spectroscopic data of the complexes in organic solution and in the solid state. Maximum absorption wavelength $\left(\lambda_{a b s}\right)$, maximum phosphorescence and photoluminescence wavelengths $\left(\lambda_{\mathrm{P}}\right.$ and $\left.\lambda_{\mathrm{PL}}\right)$, phosphorescence and photoluminescence quantum yields ( $\Phi_{\mathrm{P}}$ and $\Phi_{\mathrm{PL}}$ ), $\tau$ main lifetime. For solutions, complex concentration $\sim 3.5 \times 10^{-5} \mathrm{M}, \lambda_{\mathrm{ex}}=380 \mathrm{~nm}$

\begin{tabular}{|c|c|c|c|c|c|c|c|c|c|c|c|}
\hline & \multicolumn{5}{|c|}{ Dichloromethane ${ }^{a}$} & \multicolumn{3}{|c|}{ Water/acetonitrile. $95: 5 \mathrm{v} / \mathrm{v}^{\mathrm{b}}$} & \multicolumn{3}{|c|}{ Solid state } \\
\hline Compounds & $\begin{array}{l}\lambda_{\mathrm{abs}} \\
{[\mathrm{nm}]}\end{array}$ & $\begin{array}{l}\varepsilon\left[\mathrm{M}^{-1}\right. \\
\left.\mathrm{cm}^{-1}\right]\end{array}$ & $\begin{array}{l}\lambda_{\mathrm{P}} \\
{[\mathrm{nm}]}\end{array}$ & $\tau[\mathrm{ns}]$ & $\begin{array}{l}\tau \\
{[n s]}\end{array}$ & $\begin{array}{l}\lambda_{\text {abs }} \\
\text { [nm] }\end{array}$ & $\begin{array}{l}\lambda_{\mathrm{P}} \\
{[\mathrm{nm}]}\end{array}$ & $\Phi_{\mathrm{P}}$ & $\begin{array}{l}\lambda_{\mathrm{PL}} \\
{[\mathrm{nm}]}\end{array}$ & $\Phi_{\mathrm{PL}}$ & $\tau[\mathrm{ns}]$ \\
\hline ReL1c $^{c}$ & $\begin{array}{l}296, \\
384\end{array}$ & $\begin{array}{l}27800, \\
3900\end{array}$ & 628 & 0.017 & 74.7 & - & - & - & $584^{d}$ & 0.065 & 338 \\
\hline ReL3 & $\begin{array}{l}305 \\
383\end{array}$ & $\begin{array}{l}33400, \\
4300\end{array}$ & 627 & 0.017 & 100 & 310 & 582 & 0.090 & 565 & 0.21 & 890 \\
\hline ReL4 & $\begin{array}{l}310 \\
388\end{array}$ & $\begin{array}{l}29600, \\
5100\end{array}$ & 632 & 0.012 & 80 & 30 & 574 & 0.090 & 542 & 0.55 & 563 \\
\hline
\end{tabular}

a Samples bubbled with Ar for 5 min before measurements. b Undegassed solutions. c Data from ref. 8. $d$ This work.
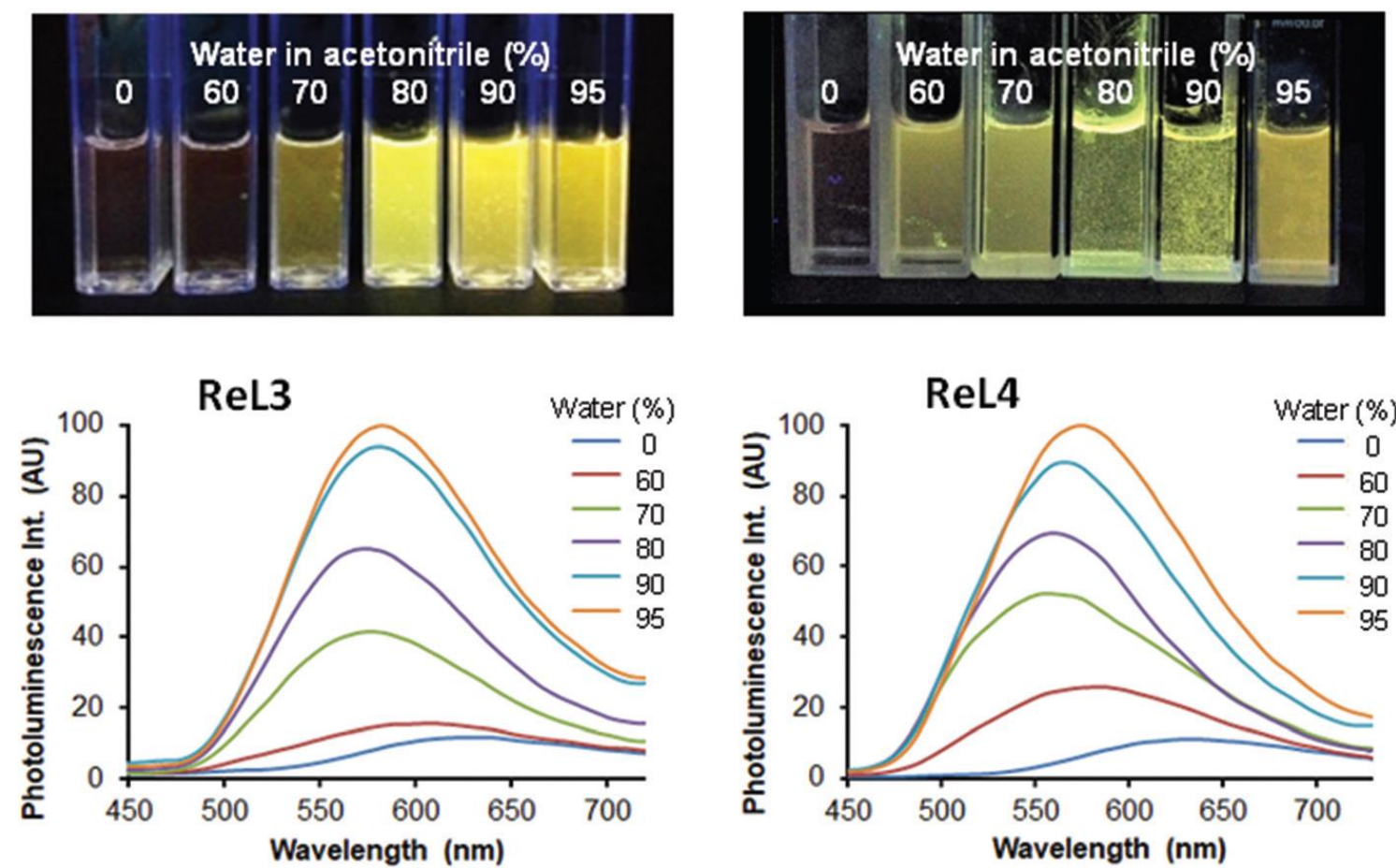

Figure 9. Bottom: Emission spectra of complexes ReL3 and ReL4 at $5.2 \times 10^{-5} \mathrm{M}$ and $3.6 \times 10^{-5} \mathrm{M}$, respectively, in acetonitrile solutions containing $0,60,70,80,90$ and $95 \%$ water (from bottom to top), $\lambda_{\mathrm{ex}}=380 \mathrm{~nm}$. Top: Corresponding samples illuminated by a hand-held UV lamp (365 nm).

To complete this study, a comparison was made with the powders of ReL3 and ReL4, obtained by crystallization in methanol at the end of the synthesis process. Obviously, the spectroscopic properties of these microcrystalline compounds differed from those of solutions and aggregates. Upon illumination by a hand-held UV lamp, ReL3 emitted golden yellow light. Its solid-state emission spectra peaked at $565 \mathrm{~nm}$ (Fig. 10) and the photoluminescence quantum yield was 0.21, i.e. 14 folds higher than in DCM solutions. In contrast, ReL4 emitted bright yellow-green light under the UV lamp. The emission band peaked at $542 \mathrm{~nm}$, with quantum yield as high as 0.55 , almost 46 times higher than in DCM solutions. Therefore, the solid-state emission spectra of ReL3 and ReL4 were blue-shifted by 16 and $32 \mathrm{~nm}$, and their photoluminescence efficiency was increased by 3 and 8 folds, respectively, with respect to ReL1. Decay measurements required three components for an acceptable 
fit, as was the case for ReL1 (Table S18 ${ }^{\dagger}$ ). The longest lifetime component ( $890 \mathrm{~ns}$ and $563 \mathrm{~ns}$ for ReL3 and ReL4, respectively) was associated to a very high fraction of intensity. Noticeably, these values are significantly longer than in ReL1 (338 ns), possibly indicating a stabilization of the corresponding excited state. The short lifetime component could be attributed to fluorescent impurities despite the extensive purification of the compounds. Although associated to a very small fraction of intensity, the intermediate lifetime (185 and 93 ns for ReL3 and ReL4, respectively), was intriguing because it was not detected in solutions. Work is underway to determine the origin of these various lifetimes, which may arise for example from the presence of multiple emitting species in the solid state, as well as from distinct deactivation pathways for only one type of emitter. ${ }^{17}$

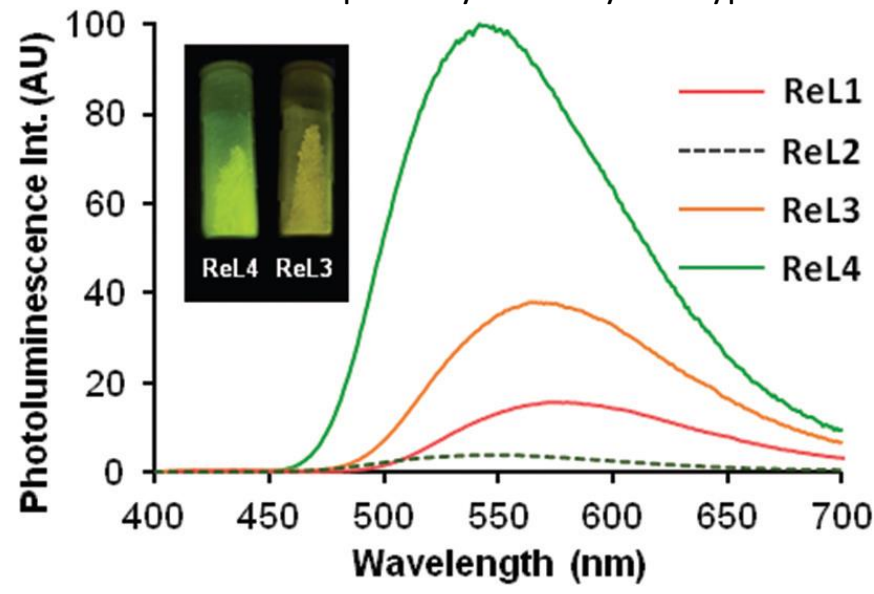

Figure 10. Comparative emission spectra of pristine powders of the four complexes: ReL1 (orange line), ReL2 (dashed green line), ReL3 (orange line) and ReL4 (green line). The intensity is proportional to the quantum yield. $\lambda_{\text {ex }}=380 \mathrm{~nm}$ for ReL1 and ReL2, $355 \mathrm{~nm}$ for ReL3 and ReL4. Inset: Samples of ReL3 and ReL4 illuminated by a hand-held UV lamp (365 nm).

\section{Conclusions}

It was shown here that the presence of the electron-donating tert-butyl group in ReL3 has very little influence on the geometry and behavior of this complex in organic solutions, with respect to ReL1. This is reminiscent of other photo-responsive compounds where tert-butyl groups placed at the periphery of the photoactive core preserve the electronic properties of the mother molecule in solution. ${ }^{18}$ Reversing the position of the PBO fragment on the pyta group in ReL4 also has little effect, as long as dissolved molecules are considered. However, remarkable differences between the complexes were observed in the solid-state emission properties. The introduction of a bulky substituent in a molecule is a strategy generally used to prevent molecular $\pi-\pi$ stacking, which is extremely detrimental to the emission of light. ${ }^{19}$ The bulkiness and structuring effect of the tert-butyl group previously allowed us to improve the molecular arrangement, and hence the photoluminescence properties, of organic PBO and phenylnaphthoxazole derivatives. ${ }^{20}$ In the present case, the tert-butyl group of ReL3 prevented any $\pi-\pi$ stacking interaction between the aromatic moieties, and led to much better solid-state emission properties with respect to ReL1. With regards to ReL4, attaching the PBO group to pyta via the phenyl ring led to a new crystal network, and strongly enhanced the photoluminescence efficiency, which is by far the best for this series of complexes. The solid state emission properties of mononuclear rhenium(I) complexes can therefore be significantly improved by introducing tiny molecular changes. The original molecular framework of ReL4 is prone to various chemical modifications, and with its superior optical properties, this complex should be the first member of a new series of highly emissive rhenium(I) luminescent probes.

\section{Experimental section}

\section{General methods}

All purchased chemicals were of the highest purity commercially available and used without further purification. Analytical grade solvents were used and not further purified unless specified. Reactions 
were monitored by analytical thin layer chromatography (TLC) on Kieselgel 60 F254 (Merck). Chromatography purification was conducted using silica gel or neutral alumina obtained from Merck. NMR, mass and infrared spectra were obtained in the relevant 'Services communs de l'Institut de Chimie de Toulouse, Université de Toulouse III-Paul-Sabatier'. ${ }^{1} \mathrm{H}$ - and ${ }^{13} \mathrm{C}-\mathrm{NMR}$ spectra were measured with Bruker Avance DRX $500 \mathrm{MHz}$ or Bruker Avance $300 \mathrm{MHz}$. Attributions of the signals were made using 2D NMR data (COSY, HSQC and HMBC). Protons and carbon atoms were numbered according to Fig. S10. $+\mathrm{App}=$ Apparent; ${ }^{*}=$ The multiplicity of the signal is more complex as it is part of an $A A^{\prime} X X^{\prime}$ system. Electrospray mass spectra were obtained using a QTRAP Applied Biosystems spectrometer and high-resolution mass spectra (HRMS) were recorded using an LCT Premier Waters spectrometer. Desorption chemical ionization (DCl) mass spectra $\left(\mathrm{NH}_{3}\right.$ or $\left.\mathrm{CH}_{4}\right)$ were obtained on a DSQ II Thermofisher apparatus. Infrared spectra were obtained on a Nexus Thermonicolet apparatus with DTGS as the detector. The microanalyses were performed with a PerkinElmer 2400 elemental analyzer in the 'Service d'Analyse Chimique du Laboratoire de Chimie de Coordination de Toulouse' (LCC, Toulouse).

2-(4-tert-Butylphenyl)-6-nitrobenzoxazole (1). A mixture of 2-amino-5-nitrophenol (2.31 g, $15 \mathrm{mmol})$, 4-tert-butylbenzoic acid $(2.67 \mathrm{~g}, 15 \mathrm{mmol})$ and polyphosphoric acid $(24 \mathrm{~g})$ was heated to $120^{\circ} \mathrm{C}$ with stirring for $16 \mathrm{~h}$. After reaction, iced water $(100 \mathrm{~mL})$ was added. The resulting mixture was neutralized with $10 \% \mathrm{NaOH}$ solution and extracted with ethyl acetate $(3 \times 60 \mathrm{~mL})$. All organic layers were combined, washed with water, dried over anhydrous MgSO4, filtered and concentrated to dryness. The residue was purified by column chromatography on silica gel using ethyl acetate/petroleum ether 1: $10 \mathrm{v} / \mathrm{v}$, and 1 was obtained as a yellow solid ( $3.33 \mathrm{~g}$, yield $75 \%) .{ }^{1} \mathrm{H} \mathrm{NMR}(300 \mathrm{MHz}, \mathrm{CDCl} 3): \delta(\mathrm{ppm})$ $=8.49(\mathrm{~d}, \mathrm{~J}=1.8 \mathrm{~Hz}, 1 \mathrm{H}), 8.33(\mathrm{dd}, \mathrm{J}=2.2,8.8 \mathrm{~Hz}, 1 \mathrm{H}), 8.24-8.19(\mathrm{~m}, 2 \mathrm{H}), 7.84(\mathrm{~d}, \mathrm{~J}=8.8 \mathrm{~Hz}, 1 \mathrm{H}), 7.61-$ $7.57(\mathrm{~m}, 2 \mathrm{H}), 1.39(\mathrm{~s}, 9 \mathrm{H}, \mathrm{t}-\mathrm{Bu})$.

2-(4-tert-Butylphenyl)-6-aminobenzoxazole (2). To a solution of 1 (1.72 g, $5.8 \mathrm{mmol})$ in $\mathrm{MeOH} / \mathrm{CH} 2 \mathrm{Cl} 2$ $(1: 2 \mathrm{v} / \mathrm{v}, 30 \mathrm{~mL})$ was added $10 \% \mathrm{Pd} / \mathrm{C}(30 \% \mathrm{w} / \mathrm{w}, 0.52 \mathrm{~g})$ and the mixture was stirred at room temperature for $24 \mathrm{~h}$ under 6 bars pressure of $\mathrm{H}_{2}$. After reaction, the mixture was filtered twice to remove the catalyst. The filtrate was concentrated to dryness and purified by column chromatography on silica gel using ethyl acetate/petroleum ether $1: 3 \mathrm{v} / \mathrm{v}$ as the eluent, to afford $\mathbf{2}$ as a pale white solid (1.27 g, yield 82\%). ${ }^{1} \mathrm{H}$ NMR $\left(300 \mathrm{MHz}, \mathrm{CDCl}_{3}\right): \delta(\mathrm{ppm})=8.12-8.08(\mathrm{~m}, 2 \mathrm{H}), 7.53-7.50(\mathrm{~m}, 3 \mathrm{H}), 6.87$ (dd, J = 2.2, 0.5 Hz, 1H), 6.70 (dd, J = 8.4, $2.2 \mathrm{~Hz}, 1 \mathrm{H}), 1.36$ (s, 9H, t-Bu). ESI-MS: m/z $267.1\left([\mathrm{M}+\mathrm{H}]^{+}\right.$ calcd for C17H19N2O, 267.1).

$\mathrm{N}, \mathrm{N}$-Dimethyl-N'-picolinoylformohydrazonamide (3). A mixture of pyridine-2-carbohydrazide $(0.82 \mathrm{~g}, 6$ $\mathrm{mmol})$ and $\mathrm{N}, \mathrm{N}$-dimethylformamide dimethyl acetal $(1.06 \mathrm{~mL}, 8 \mathrm{mmol})$ in $\mathrm{CH}_{2} \mathrm{Cl}_{2}(20 \mathrm{~mL})$ was stirred at reflux for $2 \mathrm{~h}$. After the consumption of pyridine-2-carbohydrazide, the solvent was evaporated and the resulting precipitate was purified by column chromatography using $\mathrm{CH}_{3} \mathrm{OH} / \mathrm{CH}_{2} \mathrm{Cl}_{2}$ 1: $10 \mathrm{v} / \mathrm{v}$ as eluent to afford 3 as a yellow solid (1.09 g, yield 95\%). ${ }^{1} \mathrm{H}$ NMR $\left(300 \mathrm{MHz}, \mathrm{CDCl}_{3}\right): \delta(\mathrm{ppm})=10.04(\mathrm{~s}$, $1 \mathrm{H}, \mathrm{NH}), 8.49$ (ddd, J = 2.6, 1.7, 0.9 Hz, 1H), $8.19(\mathrm{dt}, \mathrm{J}=7.8,1.1 \mathrm{~Hz}, 1 \mathrm{H}), 7.96(\mathrm{~s}, 1 \mathrm{H}, \mathrm{HCVN}), 7.83(\mathrm{td}, \mathrm{J}$ = 7.6, 1.7 Hz, 1H), 7.38 (ddd, J = 7.6, 4.8, $1.3 \mathrm{~Hz}, 1 \mathrm{H}), 2.93(\mathrm{~s}, 6 \mathrm{H}, 2 \mathrm{CH} 3) . \mathrm{DCl} / \mathrm{NH} 3-\mathrm{MS}: \mathrm{m} / \mathrm{z} 193.1$ ([M + $\mathrm{H}]+$ calcd for $\left.\mathrm{C}_{9} \mathrm{H}_{13} \mathrm{~N}_{4} \mathrm{O}, 193.1\right)$.

2-(4-tert-Butylphenyl)-6-(3-(pyridin-2-yl)-4H-1,2,4-triazol-4-yl) benzoxazole (L3). To a mixture of 2 (0.38 $\mathrm{g}, 1.4 \mathrm{mmol})$ and $3(0.27 \mathrm{~g}, 1.4 \mathrm{mmol})$ in $\mathrm{CH}_{3} \mathrm{CN}(10 \mathrm{~mL})$ was added acetic acid $(1 \mathrm{~mL})$. The resulting mixture was refluxed at $90{ }^{\circ} \mathrm{C}$ with stirring for $24 \mathrm{~h}$. After cooling to room temperature, the mixture was concentrated to dryness and purified by column chromatography using $\mathrm{CH}_{3} \mathrm{OH} / \mathrm{CH}_{2} \mathrm{Cl}_{2} 1: 10 \mathrm{v} / \mathrm{v}$ as eluent to afford a light yellow solid. Then, the crude product was washed twice with methanol $(2 \times 10$ $\mathrm{mL}$ ) and dried in vacuum to afford $\mathrm{L3}$ as a white powder $(0.35 \mathrm{~g}$, yield $64 \%) .{ }^{1} \mathrm{H}$ NMR (500 MHz, DMSOd6): $\delta(p p m)=8.97\left(\mathrm{~s}, 1 \mathrm{H}, \mathrm{H} 5^{\prime}\right), 8.36$ (ddd, J = 4.8, 1.8, $\left.0.9 \mathrm{~Hz}, 1 \mathrm{H}, \mathrm{H} 6^{\prime \prime}\right), 8.15$ (app. $\mathrm{d}^{*}, \mathrm{~J}=8.8 \mathrm{~Hz}, 2 \mathrm{H}$, $\mathrm{Hb}, \mathrm{f}$ ), 8.10 (dt, J = 7.9, $\left.1.1 \mathrm{~Hz}, 1 \mathrm{H}, \mathrm{H3} 3^{\prime \prime}\right), 8.00$ (dd, J = 2.0, 0.5 Hz, 1H, H7), 7.99-7.97 (m, 1H, H4"), 7.86 (dd, J = 8.4, $0.5 \mathrm{~Hz}, 1 \mathrm{H}, \mathrm{H} 4$ ), 7.66 (app. d*, J = 8.8 Hz, 2H, Hc,e), 7.42 (ddd, J = 7.6, 4.8, 1.2 Hz, 1H, H5"), 
7.39 (dd, J = 8.4, $2.0 \mathrm{~Hz}, 1 \mathrm{H}, \mathrm{H} 5), 1.34$ (s, 9H, t-Bu). ${ }^{13} \mathrm{C}$ NMR (125 MHz, DMSO-d6): $\delta(p p m)=164.4$, 155.9, 152.1, 150.2, 149.5, 146.9 (C3'), 142.1, 137.8, 132.8, 127.8, 126.8, 125.0, 124.4, 123.9, 123.8, 122.2, 120.0, 109.8, 35.4 (Cqt-Bu), 31.3 (CH3). DCl/CH $\mathrm{CH}_{4}$-HMS: $\mathrm{m} / \mathrm{z} 396.1813$ ([M + H]+: calcd for $\left.\mathrm{C}_{24} \mathrm{H}_{22} \mathrm{~N}_{5} \mathrm{O}, 396.1824\right)$.

2-(4-Aminophenyl) benzoxazole (4). A mixture of 2-aminophenol (2.21 g, $0.02 \mathrm{~mol})$, 4-aminobenzoic acid $(2.75 \mathrm{~g}, 0.02 \mathrm{~mol})$ and polyphosphoric acid $(40 \mathrm{~g}, 0.4 \mathrm{~mol})$ was stirred at $220^{\circ} \mathrm{C}$ for $4 \mathrm{~h}$. Distilled water $(200 \mathrm{~mL})$ was added to the mixture and a saturated solution of $\mathrm{NaHCO} 3$ was slowly poured into the solution until no bubbling was detected. After filtration, washing with water and drying, the solid obtained was sublimated at $240{ }^{\circ} \mathrm{C}$ under vacuum. Compound 4 was obtained as a pink solid $(2.72 \mathrm{~g}$, yield: $65 \%)$. $1 \mathrm{H} \mathrm{NMR} \mathrm{(300} \mathrm{MHz,} \mathrm{CDCl3):} \delta(\mathrm{ppm})=8.12-8.01(\mathrm{~m}, 2 \mathrm{H}), 7.76-7.65(\mathrm{~m}, 1 \mathrm{H}), 7.58-7.48(\mathrm{~m}$, $1 \mathrm{H}), 7.33-7.27(\mathrm{~m}, 2 \mathrm{H}), 6.82-6.70(\mathrm{~m}, 2 \mathrm{H}) . \mathrm{DCl} / \mathrm{CH}_{4}-\mathrm{MS}: \mathrm{m} / \mathrm{z} 211.09\left([\mathrm{M}+\mathrm{H}]^{+}\right.$calcd for $\mathrm{C}_{13} \mathrm{H}_{11} \mathrm{~N}_{2} \mathrm{O}$, 211.09).

2-(4-(3-(Pyridin-2-yl)-4H-1,2,4-triazol-4-yl)phenyl)benzoxazole (L4). Reacting 5 (0.42 g, $2.0 \mathrm{mmol}$ ) and $3(0.38 \mathrm{~g}, 2.0 \mathrm{mmol})$ according to the procedure described for $\mathbf{L} \mathbf{3}, \mathbf{L} \mathbf{4}$ was obtained as a white powder $(0.29 \mathrm{~g}$, yield $43 \%)$ after purification on column chromatography (silica gel, ethyl acetate) and two washings with methanol. ${ }^{1} \mathrm{H}$ NMR $\left(500 \mathrm{MHz}\right.$, DMSO-d6): $\delta(\mathrm{ppm})=9.03\left(\mathrm{~s}, 1 \mathrm{H}, \mathrm{H} 5^{\prime}\right), 8.41$ (ddd, J = 4.8, $1.8,1.0 \mathrm{~Hz}, 1 \mathrm{H}, \mathrm{H} \mathrm{6}$ 6) $^{\prime \prime}, 8.28$ (app. $\left.\mathrm{d}^{*}, \mathrm{~J}=8.5 \mathrm{~Hz}, 2 \mathrm{H}, \mathrm{Hb}, \mathrm{f}\right), 8.12$ (dt, J = 7.8, $1.2 \mathrm{~Hz}, 1 \mathrm{H}, \mathrm{H3}{ }^{\prime \prime}$ ), 8.02 (td, J $\left.=7.6,1.8 \mathrm{~Hz}, 1 \mathrm{H}, \mathrm{H} 4^{\prime \prime}\right), 7.86-7.81(\mathrm{~m}, 2 \mathrm{H}, \mathrm{H} 4,7), 7.62$ (app. $\mathrm{d}^{*}, 2 \mathrm{H}, \mathrm{Hc}, \mathrm{e} \mathrm{d}, \mathrm{J}=8.5 \mathrm{~Hz}$ ), 7.49-7.43 (m, $\left.3 \mathrm{H}, \mathrm{H} 5,6,5^{\prime \prime}\right) .{ }^{13} \mathrm{C}$ NMR $(125 \mathrm{MHz}$, DMSO-d6): $\delta(\mathrm{ppm})=161.8,151.8,150.8,149.5,146.7,146.5$ (C3'), 141.9, 138.4, 138.0, 128.5, 127.3, 126.9, 126.3, 125.5, 125.1, 124.4, 120.5, 111.5. DCl/CH4-HRMS: $\mathrm{m} / \mathrm{z} 340.1194\left([\mathrm{M}+\mathrm{H}]+\right.$ calcd for $\left.\mathrm{C}_{20} \mathrm{H}_{14} \mathrm{~N}_{5} \mathrm{O}, 340.1198\right)$.

\section{General procedure for the preparation of tricarbonylrhenium(I) complexes}

A mixture of ligand and $\left[\operatorname{Re}(\mathrm{CO})_{5} \mathrm{Cl}\right]\left(1.15\right.$ eq.) in methanol was stirred for $16 \mathrm{~h}$ at $65{ }^{\circ} \mathrm{C}$. After consumption of the ligand, the mixture was cooled to room temperature and filtered, the precipitate was purified by chromatography on silica gel using ethyl acetate as eluent to afford the desired product.

ReL3. $130 \mathrm{mg}(0.33 \mathrm{mmol})$ of $\mathrm{L} 3$ and $130 \mathrm{mg}(0.36 \mathrm{mmol})$ of $\left[\operatorname{Re}(\mathrm{CO})_{5} \mathrm{Cl}\right]$ afforded ReL3 as a yellow solid (164 mg, yield 71\%). ${ }^{1} \mathrm{H}$ NMR (500 MHz, DMSO-d6): $\delta(p p m)=9.30\left(\mathrm{~s}, 1 \mathrm{H}, \mathrm{H} 5^{\prime}\right), 9.10$ (ddd, J = 2.2, 1.5, $0.8 \mathrm{~Hz}, 1 \mathrm{H}, \mathrm{H6}^{\prime \prime}$ ), 8.47 (br s, $1 \mathrm{H}, \mathrm{H7}$ ), 8.22 (app d*, J = 8.7 Hz, 2H, Hb,f), 8.13 (dd, J = 8.5, $0.5 \mathrm{~Hz}, 1 \mathrm{H}, \mathrm{H}$ ), 8.07 (td, J = 7.9, 1.6 Hz, 1H, H4"), 7.76-7.74 (m, 1H, H5"), 7.72 (app d*, J = 8.8 Hz, 2H, Hc,e), 7.24 (ddd, $\left.\mathrm{J}=2.1,1.2,0.9 \mathrm{~Hz}, 1 \mathrm{H}, \mathrm{H3}{ }^{\prime \prime}\right), 1.36$ (s, 9H, t-Bu). 13C NMR (125 MHz, DMSO-d6): $\delta(\mathrm{ppm})=198.3,197.7$, 189.5 (CO), 165.4, 156.3, 155.1, 155.0, 150.7, 149.0 (C5'), 144.5, 144.3, 141.2, 129.1, 128.8, 128.1, 126.9, 124.6, 123.8, 123.5, 121.5, 115.1, 111.3, 35.4 (Cqt-Bu), $31.3(\mathrm{CH} 3) . \quad \mathrm{DCl} / \mathrm{CH}_{4}-\mathrm{HRMS}: \mathrm{m} / \mathrm{z}$

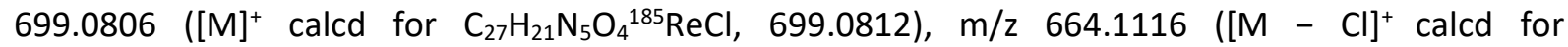
$\mathrm{C}_{27} \mathrm{H}_{21} \mathrm{~N}_{5} \mathrm{O}_{4}{ }^{185} \mathrm{Re}$ 664.1123); Anal. calcd (\%) for $\mathrm{C}_{27} \mathrm{H}_{21} \mathrm{~N}_{5} \mathrm{O}_{4} \mathrm{ReCl}$ : C 46.25, H 3.02, N 9.99; found: $\mathrm{C} 45.97$, H 3.53, N 10.08. IR(ATR): v(CO) $=2028,1920,1883 \mathrm{~cm}^{-1}$.

ReL4. $130 \mathrm{mg}(0.38 \mathrm{mmol})$ of $\mathbf{L} 4$ and $158 \mathrm{mg}(0.44 \mathrm{mmol})$ of $\left[\operatorname{Re}(\mathrm{CO})_{5} \mathrm{Cl}\right]$ afforded ReL4 as a yellow solid (197 mg, yield 80\%). ${ }^{1} \mathrm{H}$ NMR (500 MHz, DMSO-d6): $\delta(p p m)=9.33\left(\mathrm{~s}, 1 \mathrm{H}, \mathrm{H} 5^{\prime}\right), 9.11$ (ddd, J = 5.4, 1.5, $0.7 \mathrm{~Hz}, 1 \mathrm{H}, \mathrm{H6} 6^{\prime \prime}$ ), 8.55 (app. dd*, J = 7.6, $1.3 \mathrm{~Hz}, 2 \mathrm{H}, \mathrm{Hb}, \mathrm{f}$ ), 8.12 (td, J = 7.9, $1.5 \mathrm{~Hz}, 1 \mathrm{H}, \mathrm{H} 4^{\prime \prime}$ ), 8.08 (app. br d*, 2H, $9 \mathrm{~Hz}, \mathrm{Hc}, \mathrm{e}), 7.92-7.87(\mathrm{~m}, 2 \mathrm{H}, \mathrm{H7}, 4), 7.76$ (ddd, J = 6.7, 5.5, 1.2 Hz, 1H, H5"), 7.54-7.47 (m, $2 \mathrm{H}, \mathrm{H} 5,6), 7.29$ (dt, J = 8.1, $\left.1.1 \mathrm{~Hz}, 1 \mathrm{H}, \mathrm{H3}{ }^{\prime \prime}\right) .{ }^{13} \mathrm{C}$ NMR $(125 \mathrm{MHz}, \mathrm{DMSO}-\mathrm{d} 6): \delta(\mathrm{ppm})=198.3,197.7$, 189.5 (CO), 161.4, 155.0, 154.8, 150.9, 148.5 (CH5'), 144.5, 141.8, 141.1, 135.2, 129.8, 129.5, 128.8, 128.6, 126.8, 125.8, 123.7, 120.7, 111.7. ESI/CH ${ }_{4}$-HRMS: $\mathrm{m} / \mathrm{z} 608.0502$ ([M - Cl] ${ }^{+}$calcd for

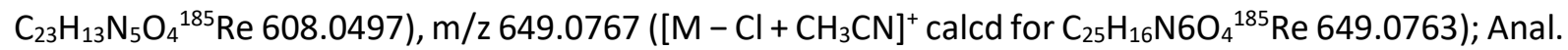
calcd (\%) for $\mathrm{C}_{23} \mathrm{H}_{13} \mathrm{~N}_{5} \mathrm{O}_{4} \mathrm{ReCl}$ : C 42.83, $\mathrm{H}$ 2.03, N 10.86; found: C 42.58, H 1.98, N 10.62. IR(ATR): v(CO) $=2021,1934,1887 \mathrm{~cm}^{-1}$. 


\section{X-ray crystallography}

Crystal data were collected at $193 \mathrm{~K}$ on a Bruker AXS Quazar APEX II diffractometer using a $30 \mathrm{~W}$ aircooled microfocus source $(\mathrm{ImS})$ with focusing multilayer optics using MoK $\alpha$ radiation (wavelength = $0.71073 \AA$ Å). Phi- and omega-scans were used. The structures were solved by direct methods (SHELXS 97) or using intrinsic phasing method (ShelXT).21,22 All nonhydrogen atoms were refined anisotropically using the leastsquare method on F2.22 Selected crystallographic data are collected in Table 2.

Table 2. Selected crystallographic data of complexes ReL3 and ReL4

\begin{tabular}{|c|c|c|}
\hline & ReL3 & ReL4 \\
\hline Empirical formula & $\mathrm{C}_{27} \mathrm{H}_{21} \mathrm{ClN}_{5} \mathrm{O}_{4} \mathrm{Re}$ & $\mathrm{C}_{23} \mathrm{H}_{13} \mathrm{ClN}_{5} \mathrm{O}_{4} \mathrm{Re}$ \\
\hline Formula weight & 701.15 & 645.04 \\
\hline Crystal system & Triclinic & Orthorhombic \\
\hline Space group & $\mathrm{P}^{-1} 1$ & P212121 \\
\hline \multicolumn{3}{|l|}{ Unit cell dimensions } \\
\hline $\mathrm{a}(\AA)$ & $12.1819(9)$ & $8.0086(3)$ \\
\hline $\mathrm{b}(\AA)$ & $13.8261(10)$ & $10.5904(4)$ \\
\hline$c(\AA)$ & $20.0905(14)$ & $25.9678(9)$ \\
\hline$\alpha\left(^{\circ}\right)$ & $71.646(4)$ & 90 \\
\hline$\beta\left(^{\circ}\right)$ & $75.370(4)$ & 90 \\
\hline$\gamma\left({ }^{\circ}\right)$ & $85.803(4)$ & 90 \\
\hline Volume $\left(\AA^{3}\right)$ & $3107.5(4)$ & $2202.44(14)$ \\
\hline$Z$ & 4 & 4 \\
\hline Density (calcd) $\left(\mathrm{g} \mathrm{cm}^{-3}\right)$ & 1.499 & 1.945 \\
\hline Crystal size $(\mathrm{mm} 3)$ & $0.100 \times 0.080 \times 0.020$ & $0.100 \times 0.100 \times 0.020$ \\
\hline Reflections collected & 63669 & 60111 \\
\hline Independent reflections & 9032 & 5251 \\
\hline $\mathrm{R}_{\text {int }}$ & 0.0857 & 0.0899 \\
\hline Restraints/parameters & $336 / 816$ & $0 / 307$ \\
\hline Final R1 index $I>2 \sigma(I)$ & 0.0642 & 0.0281 \\
\hline wR2 (all data) & 0.2480 & 0.0441 \\
\hline Largest diff. peak and hole (e $\AA$ - -3 ) & 1.007 and -2.619 & 1.381 and -1.121 \\
\hline CCDC & 1922851 & 1922852 \\
\hline
\end{tabular}

\section{Computational details}

The GAUSSIAN09 program package ${ }^{23}$ was employed for all calculations with the aid of the ChemCraft visualization program. ${ }^{24}$ The ground state (SO), the first excited state (S1) and the lowest triplet state (T1) geometries of compounds were fully optimized with the restricted and unrestricted density functional theory (R-DFT and U-DFT) method using the Perdew-Burke-Ernzerhof PBE1PBE functional without symmetry constraints. ${ }^{25}$ In all calculations, the "double- $\zeta$ " quality basis set LANL2DZ with Hay and Wadt's relative effective core potential ECP (outer-core [(5s25p6)] electrons and the $(5 d 6)$ valence electrons) ${ }^{26}$ was employed for the Re atom. The $6-31+\mathrm{g}^{* *}$ basis set for $\mathrm{H}, \mathrm{C}, \mathrm{N}, \mathrm{O}$ and $\mathrm{Cl}$ atoms was used. ${ }^{27}$ The solvent effect (dichloromethane, $\varepsilon=9.08$ ) was simulated using the Self-Consistent Reaction Field (SCRF) under the Polarizable Continuum Model (PCM). ${ }^{28}$ The vibrational frequencies calculations were performed using the optimized structural parameters of compounds, to confirm that each optimized structure represents a local minimum on the potential energy surface and all eigenvalues are non-negative. On the basis of the optimized ground and excited state geometries, the absorption and emission properties were calculated by the time dependent density functional theory (TD-DFT) method at the PBE1PBE/LANL2DZ/6-31+G** level. These methods have already shown good agreement with experimental studies for different rhenium(I) complexes. ${ }^{29}$

\section{Electrochemistry}

The electrochemical properties of the new compounds were determined by cyclic voltammetry (CV) and Osteryoung square wave voltammetry (OSWV) in DCM. The solutions used during the electrochemical studies were typically $1 \times 10^{-3} \mathrm{M}$ in ligand or $6.5 \times 10^{-3} \mathrm{M}$ in complex, and $0.1 \mathrm{M}$ in 
supporting electrolyte. The supporting electrolyte $\left(\mathrm{nBu}_{4} \mathrm{~N}\right)\left(\mathrm{BF}_{4}\right)(\mathrm{Fluka}, 99 \%$ electrochemical grade) was used as received and simply degassed under Ar. DCM was dried using an MB SPS-800 solvent purification system just prior to use. The measurements were carried out with an Autolab PGSTAT100 potentiostat controlled by GPES 4.09 software. Experiments were performed at room temperature (r.t.) in a homemade airtight three-electrode cell connected to a vacuum/Ar line. The reference electrode consisted of a saturated calomel electrode (SCE) separated from the solution by a bridge compartment. The counter electrode was a Pt wire of ca. $1 \mathrm{~cm} 2$ apparent surface. The working electrode was a Pt microdisk $(0.5 \mathrm{~mm}$ diameter). Before each measurement, the solutions were degassed by bubbling Ar and the working electrode was polished with a polishing machine (Presi P230). Under these experimental conditions, $\mathrm{Fc}^{+} / \mathrm{Fc}$ is observed at $+0.55 \pm 0.01 \mathrm{~V}$ vs. SCE. OSWVs were obtained using an amplitude of $20 \mathrm{mV}$, a frequency of $20 \mathrm{~Hz}$, and a step potential of $5 \mathrm{mV}$.

\section{Spectroscopy and photophysics}

Dye solutions were prepared by gentle heating in a solvent, sonication and filtration on paper filter prior to measurement. Spectroscopic measurements in solutions were conducted at $20{ }^{\circ} \mathrm{C}$ in a temperature-controlled cell. UV-visible absorption spectra were recorded on a Hewlett Packard 8453 spectrometer. Fluorescence spectra in solutions were measured with a Xenius SAFAS spectrofluorometer using cells of $1 \mathrm{~cm}$ optical pathway. All fluorescence spectra were corrected. The fluorescence quantum yields in solution $\left(\Phi_{\mathrm{F}}\right)$ were determined using the classical formula:

$\Phi_{\mathrm{Fx}}=\left(\mathrm{A}_{\mathrm{s}} \times \mathrm{F}_{\mathrm{x}} \times \mathrm{n}_{\mathrm{x}}{ }^{2} \times \Phi_{\mathrm{Fs}}\right) /\left(\mathrm{A}_{\mathrm{x}} \times \mathrm{F}_{\mathrm{s}} \times \mathrm{n}_{\mathrm{s}}{ }^{2}\right)$ where $\mathrm{A}$ is the absorbance at the excitation wavelength, $\mathrm{F}$ the area under the fluorescence curve and $\mathrm{n}$ the refraction index. Subscripts $\mathrm{s}$ and $\mathrm{x}$ refer to the standard and to the sample of unknown quantum yield, respectively. Coumarin $153\left(\Phi_{\mathrm{F}}=0.53\right)$ in ethanol was used as the standard..$^{30}$ The absorbance of the solutions was equal or below 0.055 at the excitation wavelength. The error on the quantum yield values is estimated to be about $10 \%$.

The solid state spectrum of ReL1, previously recorded on a Xenius SAFAS spectrofluorometer, was corrected using a homemade correction curve. Solid state spectra and photoluminescence quantum yields of ReL3 and ReL4 were recorded on a Fluorolog spectrofluorometer from HORIBA Scientific equipped with an integrating sphere. Solid samples were deposited on a metal support and luminescence spectra were corrected. The absolute photoluminescence quantum yield values $\left(\Phi_{P}\right)$ were determined by a method based on the one developed by de Mello et al., ${ }^{31}$ as described elsewhere. ${ }^{8}$ The error was estimated to be about $20 \%$.

Fluorescence decays curves in dilute DCM solutions ( $A b s$ at $\lambda_{\mathrm{ex}}<0.1$ ) were recorded by time-correlated single-photon counting method (TCSPC). Solutions were first bubbled with Ar for 5 min before measurements. An oscillating femtosecond titanium-sapphire laser (Tsunami, Spectra-Physics) pumped by a double Nd: YVO4 laser (Millenia Xs, Spectra-Physics) was used for excitation. Harmonic generators were employed to tune to $\lambda$ ex $=380 \mathrm{~nm}$. Emitted photons were detected at $90^{\circ}$ through a monochromator by means of a Hamamatsu MC P $3809 \mathrm{U}$ photomultiplier connected to a SPC-630 TCSPC module from Becker and Hickl. The instrumental response function was recorded after each decay curve. The decay curves were analyzed with reconvolution and global non-linear leastsquares minimization method using the Globals software package developed at the Laboratory for Fluorescence Dynamics at the University of Illinois at Urbana-Champaign.

In the solid state, decay curves were measured by an LP920- K spectrometer equipped with a Xenon lamp (450 W pulse), a monochromator with $300 \mathrm{~mm}$ focus, and a photomultiplier (Hamamatsu R928). Quartz sample holders $(0.2 \mathrm{~mm})$ from Starna were used. The sample was excited by an oscillating $\mathrm{Nd}$ :YAG nanosecond laser (7-8 ns) with a repetition rate of $10 \mathrm{~Hz}$ at its third harmonic generation (355 $\mathrm{nm})$. The instrumental response function was recorded with each set of decay curves. The data were analyzed with reconvolution using the $L 900$ software.

\section{Conflicts of interest}

There are no conflicts to declare. 


\section{Acknowledgements}

J. Wang thanks the Chinese Scholarship Council (CSC) for a PhD funding. The calculations were carried out in the Wroclaw Centre for Networking and Supercomputing, Poland (http://www.wcss.pl). We are also grateful to Dr Stéphane Balayssac for his help in interpreting NMR spectra, to Dr Alix SourniaSaquet (LCC-CNRS) for electrochemical measurements and to Dr Rémi Métivier for fruitful discussions. J. P. Calupitan and C. Allain also thank the European Research Council for funding (ERC StG-715757 MECHANO-FLUO to C. A.), and thank Arnaud Brosseau (PPSM) for his help with the time-resolved fluorescence measurements.

\section{References}

1 ( a) V. Sathish, A. Ramdass, P. Thanasekaran, K.-L. Lu and S. Rajagopal, J. Photochem. Photobiol., C, 2015, 23, 25-44; (b) L. Ravotto and P. Ceroni, Coord. Chem. Rev., 2017, 346, 62-76.

2 M. Wrighton and D. L. Morse, J. Am. Chem. Soc., 1974, 96, 998-1003.

3 (a) L. C.-C. Lee, K.-K. Leung and K. K.-W. Lo, Dalton Trans., 2017, 46, 16357-16380; (b) K. K.-W. Lo, Acc. Chem. Res., 2015, 48, 2985-2995; (c) R. G. Balasingham, M. P. Coogan and F. L. Thorp-Greenwood, Dalton Trans., 2011, 40, 11663-11674.

4 (a) M. V. Werrett, G. S. Huff, S. Muzzioli, V. Fiorini, S. Zacchini, B. W. Skelton, A. Maggiore, J. M. Malicka, M. Cocchi, K. C. Gordon, S. Stagni and M. Massi, Dalton Trans., 2015, 44, 8379-8393; (b) T. Klemens, A. ŚwitlickaOlszewska, B. Machura, M. Grucela, H. Janeczek, E. SchabBalcerzak, A. Szlapa, S. Kula, S. Krompiec, K. Smolarek, D. Kowalska, S. Mackowski, K. Erfurt and P. Lodowski, RSC Adv., 2016, 6, 56335-56352; (c) A. Świtlicka, T. Klemens, B. Machura, E. Schab-Balcerzak, K. Laba, M. Lapkowski, M. Grucela, J. Nycz, M. Szala and M. Kania, RSC Adv., 2016, 6, 112908-112918; (d) G.-W. Zhao, J.-H. Zhao, Y.-X. Hu, D.-Y. Zhang and X. Li, Synth. Met., 2016, 212, 131-141; (e) N. Azzarelli, S. Ponnala, A. Aguirre, S. J. Dampf, M. P. Davis, M. T. Ruggiero, V. Lopez Diaz, J. W. Babich, M. Coogan, T. Korter, R. P. Doyle and J. Zubieta, Inorg. Chim. Acta, 2019, 489, 301309.

5 (a) V. Sathish, A. Ramdass, Z.-Z. Lu, M. Velayudham, P. Thanasekaran, K.-L. Lu and S. Rajagopal, J. Phys. Chem. B, 2013, 117, 14358-14366; (b) B. Manimaran, P. Thanasekaran, T. Rajendran, R.-J. Lin, I.-J. Chang, G.-H. Lee, S.M. Peng, S. Rajagopal and K.-L. Lu, Inorg. Chem., 2002, 41, 5323-5325; (c) Y.-J. Pu, R. E. Harding, S. G.

Stevenson, E. B. Namdas, C. Tedeschi, J. P. J. Markham, R. J. Rummings, P. L. Burn and I. D. W. Samuel, J. Mater. Chem., 2007, 17, 4255-4264; (d) V. Sathish, E. Babu, A. Ramdass, Z.-Z. Lu, M. Velayudham, P. Thanasekaran, K.L. Lu and S. Rajagopal, Talanta, 2014, 130, 274-279.

6 E. Quartapelle Procopio, M. Mauro, M. Panigati, D. Donghi, P. Mercandelli, A. Sironi, G. D’Alfonso and L. De Cola, J. Am. Chem. Soc., 2010, 132, 14397-14399.

7 (a) Q. Wei, Y. Dai, C. Chen, L. Shi, Z. Si, Y. Wan, Q. Zuo, D. Han and Q. Duan, J. Mol. Struct., 2018, 1171, 786792; (b) M. T. Gabr and F. C. Pigge, Dalton Trans., 2017, 46, 15040-15047; (c) T. Tao, H. Fang, Y.-X. Peng, M.-D. Zhang and W. Huang, Inorg. Chem. Commun., 2017, 84, 15-19.

8 J. Wang, B. Delavaux-Nicot, M. Wolff, S. Mallet-Ladeira, R. Métivier, E. Benoist and S. Fery-Forgues, Dalton Trans. , 2018, 47, 8087-8099.

9 C. Carayon and S. Fery-Forgues, Photochem. Photobiol. Sci., 2017, 16, 1020-1035.

10 (a) Y.-X. Li, H. Zhang, M.-N. Yu, S.-S. Wang, Y.-R. Liu, D.-Q. Lin, L.-H. Xie, Z.-Q. Lin and W. Huang, Nanoscale, 2019, 11, 5158-5162; (b) L. Zhang, J. Liu, J. Gao, R. Lu and F. Liu, RSC Adv., 2017, 7, 46354-46357; M.-M. Shi, V. C. Tung, J.-J. Nie, H.-Z. Chen and Y. Yang, Org. Electron., 2014, 15, 281-285.

11 (a) M. I. Knyazhanskii, P. V. Gilyanovskii and O. A. Osipov, Chem. Heterocycl. Compd., 1977, 13, 1160-1177; (b) R. Giménez, L. Oriol, M. Piñol, J. L. Serrano, A. I. Viñuales, T. Fisher and J. Stumpe, Helv. Chim. Acta, 2006, 89, 304-319.

12 L. Suntrup, S. Klenk, J. Klein, S. Sobottka and B. Sarkar, Inorg. Chem., 2017, 56, 5771-5783.

13 (a) R. Eychenne, S. Guizani, J.- H. Wang, C. Picard, N. Malek, P.-L. Fabre, M. Wolff, B. Machura, N. Saffon, N. Lepareur and E. Benoist, Eur. J. Inorg. Chem., 2017, 1, 69-81; (b) T. Y. Kim, A. B. S. Elliott, K. J. Shaffer, C. J. McAdam, K. C. Gordon and J. D. Crowley, Polyhedron, 2013, 52, 1391-1398.

14 Y. Zhao, R. Zhang, Y. Xu, H. Qi, X. Chen and C. Zhang, J. Electroanal. Chem., 2015, 739, 28-35.

15 (a) W. K. C. Lo, G. S. Huff, J. R. Cubanski, A. D. W. Kennedy, C. J. McAdam, D. A. McMorran, K. C. Gordon and J. D. Crowley, Inorg. Chem., 2015, 54, 1572-1587; (b) P. Datta, D. Sarkar, A. P. Mukhopadhyay, E. Lopez-Torrez, 
C. J. Pastor and C. Sinha, J. Organomet. Chem., 2011, 696, 488-495.

16 (a) Y. Zhou, J. W. Kim, R. Nandhakumar, M. J. Kim, E. Cho, Y. S. Kim, Y. H. Jang, C. Lee, S. Han, K. M. Kim, J.-J. Kim and J. Yoon, Chem. Commun., 2010, 46, 6512-6514 and references therein; (b) G. V. Loukova, Chem. Phys. Lett., 2002, 353, 244-252.

17 A. Vlček, Top. Organomet. Chem., 2010, 29, 73-114.

18 J. P. Dela Cruz Calupitan, O. Galangau, O. Guillermet, R. Coratger, T. Nakashima, G. Rapenne and T. Kawai, Eur. J. Org. Chem., 2017, 2451-2461.

19 (a) S. P. Anthony, ChemPlusChem, 2012, 77, 518-531; (b) J. Cornil, D. Beljonne, D. A. Dos Santos, J. P.

Calbert, Z. Shuai and J. L. Brédas, C. R. Acad. Sci., Ser. IV: Phys., Astrophys., 2000, 403-408.

20 (a) A. Ghodbane, P. Bordat, N. Saffon, S. Blanc and S. FeryForgues, Dyes Pigm., 2016, 125, 282-291; (b) A.

Ghodbane, J. Colléaux, N. Saffon, R. Mahiou, J.-P. Galaup and S. FeryForgues, ChemPlusChem, 2013, 78, 185191.

21 G. M. Sheldrick, Acta Crystallogr., Sect. A: Found. Adv. , 2015, 71, 3-8.

22 G. M. Sheldrick, Acta Crystallogr., Sect. C: Struct. Chem., 2015, 71, 3-8.

23 M. J. Frisch, G. W. Trucks, H. B. Schlegel, G. E. Scuseria, M. A. Robb, J. R. Cheeseman, G. Scalmani, V. Barone, B. Mennucci, G. A. Petersson, H. Nakatsuji, M. Caricato, X. Li, H. P. Hratchian, A. F. Izmaylov, J. Bloino, G. Zheng, J. L. Sonnenberg, M. Hada, M. Ehara, K. Toyota, R. Fukuda, J. Hasegawa, M. Ishida, T. Nakajima, Y. Honda, O. Kitao, H. Nakai, T. Vreven, J. A. Montgomery, J. E. Peralta, F. Ogliaro, M. Bearpark, J. J. Heyd, E. Brothers, K. N. Kudin, V. N. Staroverov, R. Kobayashi, J. Normand, K. Raghavachari, A. Rendell, J. C. Burant, S. S. Iyengar, J. Tomasi, M. Cossi, N. Rega, J. M. Millam, M. Klene, J. E. Knox, J. B. Cross, V. Bakken, C. Adamo, J. Jaramillo, R. Gomperts, R. E. Stratmann, O. Yazyev, A. J. Austin, R. Cammi, C. Pomelli, J. W. Ochterski, R. L. Martin, K. Morokuma, V. G. Zakrzewski, G. A. Voth, P. Salvador, J. J. Dannenberg, S. Dapprich, A. D. Daniels, O. Farkas, J. B. Foresman, J. V. Ortiz, J. Cioslowski and D. J. Fox, Gaussian 09, Revision A.1, Gaussian, Inc., Wallingford CT, 2009.

24 G. Zhurko and D. Zhurko, ChemCraft 1.6, 2011, http://www.chemcraftprog.com/index.html.

25 J. P. Perdew, K. Burke and M. Ernzerhof, Phys. Rev. Lett., 1996, 77, 3865-3868.

26 (a) P. J. Hay and W. R. Wadt, J. Chem. Phys., 1985, 82, 270-283; (b) P. J. Hay and W. R. Wadt, J. Chem. Phys., 1985, 82,299-310.

27 W. J. Hehre, L. Radom, P. V. R. Schleyer and J. A. Pople, Ab initio Molecular Orbital Theory, Wiley, New York, 1986.

28 (a) B. Mennucci and J. Tomasi, J. Chem. Phys., 1997, 106, 5151-2158; (b) M. Cossi, V. Barone, B. Mennucci and J. Tomasi, Chem. Phys. Lett., 1998, 286, 253-260.

29 G. Velmurugan, B. K. Ramamoorthi and P. Venuvanalingam, Phys. Chem. Chem. Phys., 2014, 16, 2115721171.

30 K. Suzuki, A. Kobayashi, S. Kaneko, K. Takehira, T. Yoshihara, H. Ishida, Y. Shiina, S. Oishi and S. Tobita, Phys. Chem. Chem. Phys., 2009, 11, 9850-9860.

31 J. C. De Mello, H. F. Wittmann and R. H. Friend, Adv. Mater., 1997, 9, 230-232. 